\title{
Highly abnormal thermotests in familial dysautonomia suggest increased cardiac autonomic risk
}

\author{
Max J Hilz, Edwin H Kolodny, Irene Neuner, Brigitte Stemper, Felicia B Axelrod
}

\begin{abstract}
Objective-Patients with familial dysautonomia have an increased risk of sudden death. In some patients with familial dysautonomia, sympathetic cardiac dysfunction is indicated by prolongation of corrected QT (QTc) interval, especially during stress tests. As many patients do not tolerate physical stress, additional indices are needed to predict autonomic risk. In familial dysautonomia there is a reduction of both sympathetic neurons and peripheral small nerve fibres which mediate temperature perception. Consequently, quantitative thermal perception test results might correlate with QTc values. If this assumption is correct, quantitative thermotesting could contribute to predicting increased autonomic risk.
\end{abstract}

Methods-To test this hypothesis, QTc intervals were determined in 12 male and eight female patients with familial dysautonomia, aged 10 to 41 years (mean 21.7 (SD 10.1) years), in supine and erect positions and postexercise and correlated with warm and cold perception thresholds assessed at six body sites using a Thermotest.

Results-Due to orthostatic presyncope, six patients were unable to undergo erect and postexercise QTc interval assessment. The QTc interval was prolonged ( $>440 \mathrm{~ms}$ ) in two patients when supine and in two additional patients when erect and postexercise. Supine QTc intervals correlated significantly with thermal threshold values at the six body sites and with the number of sites with abnormal thermal perception (Spearman's rank correlation $\mathbf{p}<0.05$ ). Abnormal Thermotest results were more frequent in the four patients with QTe prolongation and the six patients with intolerance to stress tests.

Conclusion-The results suggest that impaired thermal perception correlates with cardiac sympathetic dysfunction in patients with familial dysautonomia. Thus thermotesting may provide an alternative, albeit indirect, means of assessing sympathetic dysfunction in autonomic disorders.

(F Neurol Neurosurg Psychiatry 1998;65:338-343)

Received 4 April 1997 and in final revised form 6 March 1998

Accepted 16 March 1998
Keywords: familial dysautonomia; QTc interval; quantitative thermal testing
Cardiovascular instability is a prominent manifestation of familial dysautonomia, an autosomal recessive disorder affecting development and survival of sensory, sympathetic, and some parasympathetic neurons. ${ }^{12}$ Both hypertensive crises and orthostatic hypotension without compensatory tachycardia can occur. ${ }^{34}$ Failure of sympathetic activation with retention of parasympathetic system activity in patients with familial dysautonomia may be one of the major causes of death in this population. Survival analysis disclosed that $40 \%$ of these patients have either an unexplained death in their sleep or a sudden daytime cardiorespiratory arrest. ${ }^{5}$ To date, there are no indices to identify which patients with familial dysautonomia are at risk of sudden death. Common tests used to assess cardiac autonomic function, such as the Valsalva manoeuvre, deep metronomic breathing, or sustained handgrip test, often cannot be applied to patients with familial dysautonomia. Because of impaired coordination and abnormal breathing pattern, many patients are unable to pace their breathing, perform a Valsalva strain correctly, or sustain the handgrip without simultaneous breathholding. ${ }^{35}$ By contrast, measurements of ECG indices such as the corrected QT interval (QTc) are easily performed even in patients with poor cooperation.

Based on reports that prolongation of the QTc may be a potential marker for patients at risk for arrhythmia and sudden death, ${ }^{6-10}$ Glickstein et al ${ }^{11}$ studied this index in patients with familial dysautonomia and noted that a significant number of patients had a prolonged QTc, greater than 440 ms. Most patients with familial dysautonomia had normal QTc intervals at rest, but with the challenge of head upright tilt or exercise, by contrast with controls, a significant number of patients with familial dysautonomia had QTc prolongation. However, eight of 54 patients participating in that study did not tolerate the tilt or exercise tests. In these patients, QTc assessment is of limited use and additional non-invasive indices are required to evaluate autonomic risk.

As well as sympathetic dysfunction, patients with familial dysautonomia manifest impaired temperature perception, which is due to a decreased number of small nerve fibres. ${ }^{12}{ }^{13}$ The degree of dysfunction of $\mathrm{A} \delta$ and $\mathrm{C}$ fibres is easily assessed by quantitative thermal threshold testing. ${ }^{14-16}$ Non-invasive psychophysical assessment of warm and cold perception thresholds has proved useful in the diagnosis of small fibre neuropathies of various 
Table 1 Warm and cold perception thresholds in 20 patients with familial dysautonomia and 90 controls at six different body sites

\begin{tabular}{lll}
\hline Site & $\begin{array}{l}\text { Patients }(n=20) \\
\text { (mean }(S D))\end{array}$ & $\begin{array}{l}\text { Controls }(n=90) \\
\text { (mean }(S D)\end{array}$ \\
\hline $\begin{array}{l}\text { Cold threshold: } \\
\text { Thenar }\end{array}$ & $14.0(8.4)$ & $1.9(0.8)$ \\
Arm & $13.8(10.2)$ & $1.3(0.8)$ \\
Cheek & $10.2(7.5)$ & $1.4(0.4)$ \\
Calf & $14.0(9.8)$ & $2.8(1.9)$ \\
Foot & $15.3(10.3)$ & $2.9(1.6)$ \\
$\quad$ Shoulder & $12.0(8.2)$ & $1.4(0.7)$ \\
Warm threshold: & & \\
$\quad$ Thenar & $8.3(3.3)$ & $1.4(0.6)$ \\
Arm & $8.1(4.0)$ & $2.2(1.5)$ \\
Cheek & $6.6(4.4)$ & $0.9(0.3)$ \\
Calf & $9.3(4.0)$ & $3.5(2.2)$ \\
Foot & $8.5(4.4)$ & $3.0(1.9)$ \\
Shoulder & $6.9(3.6)$ & $1.8(1.0)$ \\
\end{tabular}

In patients with familial dysautonomia all thresholds were significantly higher than in the control group (Mann-Whitney $U$ test, $\mathrm{p}<0.005)$.

aetiologies. ${ }^{15-18}$ Correlations between impaired thermal perception and autonomic dysfunction have been described in diabetic, uraemic, and alcoholic neuropathies. ${ }^{19-21}$

We hypothesised that a similar correlation exists in familial dysautonomia, as there is neuropathological analogy of sympathetic ganglia reduction and a decrease in peripheral small nerve fibres. ${ }^{12} 1322-24$ Analogy between thermotest results and QTc values would justify substitution of Thermotesting for QTc assessment in patients intolerant to stress tests. In this study, we therefore, compared QTc intervals of patients with familial dysautonomia with their warm and cold perception thresholds determined at various body sites and to the number of body sites showing abnormal thermal perception.

\section{Material and methods}

PATIENT SELECTION

Twenty patients with familial dysautonomia participated in the study. Informed consent was obtained according to the declaration of Helsinki, with a parent signing for patients less than 21 years of age. Twelve patients were male and eight were female. They ranged in age from 10 to 41 years (mean 21.7 (SD 10.1) years). All were ambulatory patients followed up annually at the dysautonomia centre. None of the

Table 2 Frequency of impaired warm and cold perception in 20 patients with familial dysautonomia tested at six different body sites

\begin{tabular}{lllllll}
\hline & $\begin{array}{l}\text { Pathological } \\
\text { thresholds } \\
(n=20)\end{array}$ & $\begin{array}{l}\text { Thermal } \\
\text { hypoaesthesia } \\
(n=20)\end{array}$ & $\begin{array}{l}\text { Thermal } \\
\text { dysaesthesia } \\
(n=20)\end{array}$ & $\begin{array}{l}\text { Thermal } \\
\text { anaesthesia } \\
(n=20)\end{array}$ & $\begin{array}{l}\text { Incomplete } \\
\text { perception } \\
(n=20)\end{array}$ & $\begin{array}{l}\text { Paradoxical } \\
\text { perception } \\
(n=20)\end{array}$ \\
\hline $\begin{array}{l}\text { Site of cold stimulation: } \\
\text { Foot }\end{array}$ & 15 & 1 & 2 & 7 & 3 & 2 \\
Calf & 16 & 6 & 2 & 5 & 1 & 2 \\
Thenar & 17 & 7 & 3 & 2 & 3 & 2 \\
Forearm & 20 & 9 & 1 & 5 & 2 & 3 \\
Shoulder & 18 & 6 & 1 & 6 & 3 & 2 \\
Cheek & 17 & 6 & 1 & 5 & 4 & 1 \\
Site of warm stimulation: & & & & & & \\
Foot & 14 & 5 & 0 & 7 & 1 & 1 \\
Calf & 16 & 3 & 3 & 6 & 3 & 1 \\
Thenar & 20 & 12 & 2 & 1 & 3 & 1 \\
Forearm & 19 & 8 & 0 & 3 & 7 & 1 \\
Shoulder & 18 & 9 & 0 & 6 & 2 & 2 \\
Cheek & 17 & 7 & 1 & 6 & 2 & 1 \\
\hline
\end{tabular}

The number of patients with pathological thresholds represents the sum of patients with thermal hypoaesthesia, dysaesthesia, or paradoxical sensation, and patients with absent or incomplete perception of repeated stimuli. No patient presented with hyperaesthesia. Incomplete perception was defined as perceiving $<$ five of the stimuli applied for each threshold determination. subjects was taking medication known to modify the QT interval and all had normal ionised serum calcium determinations on the day of the cardiac study. The initial diagnosis of familial dysautonomia was established by Dr F B Axelrod, director of the Familial Dysautonomia Treatment and Evaluation Center, New York University, New York, NY, USA. Among the criteria used to establish the diagnosis of familial dysautonomia were Jewish Ashkenazi extraction, delayed development, failure to thrive, episodic fevers, decreased pain and temperature perception, absent deep tendon reflexes, absence of overflow tears, absence of fungiform papillae of the tongue, decreased corneal reflex, increased sweating, postural hypotension and skin blotching and hypertensive crises with stress, and absent axon flare response after intradermal histamine injection.

\section{QT MEASUREMENT}

For QT determination, a Marquette MAC-12 recorder (Marquette Electronics, Milwaukee, WI) was set to provide a lead II rhythm strip in addition to a 12 lead ECG. ${ }^{1125}$ The first ECG was obtained after the patient was supine for 10 minutes, a second after the patient was erect for five minutes, and a third immediately after the patient completed an exercise programme consisting of stepping on and off a 6 in high step for two minutes.

The QT interval was corrected for the cardiac cycle length using Bazett's formula ${ }^{26}$

$\mathrm{QTc}=$ measured QT interval/ RR interval ${ }^{1 / 2}$ With each manoeuvre, three consecutive QT intervals were measured and averaged to obtain a mean QTc. A prolonged QTc was defined as being $>440 \mathrm{~ms}^{1{ }^{127} 28}$

\section{THERMOTEST ASSESSMENT}

Warm and cold perception thresholds were psychophysically determined with a Somedic Thermotest $^{\mathrm{TM}}$ (Somedic, Stockholm, Sweden), a modification of the "Marstock" device. ${ }^{14} 29$ The thermodes operate on the Peltier principle applying continuously increasing ramp-like temperature stimuli to the tested skin area at a temperature change rate of $1^{\circ} \mathrm{C} / \mathrm{s}$. Simultaneously, a thermocouple attached to the stimulating surface continuously registers instantaneous temperature changes within $0.1^{\circ} \mathrm{C}$. Data are digitally displayed on a monitor and stored on hard disk. Thermal stimuli are generated at randomised $4 \mathrm{~s}$ to $10 \mathrm{~s}$ intervals (Senselab ${ }^{\mathrm{TM}}$, Somedic, Sweden) with preset stimulation limits, a minimum of $5^{\circ} \mathrm{C}$ and a maximum of $45^{\circ} \mathrm{C}$. Thermal stimulation started from a baseline of $32^{\circ} \mathrm{C}$. Once the subject signals stimulus perception, the temperature returns to baseline.

Warm and cold perception thresholds were determined by the "method of limits", which is comparable with the determination of hearing thresholds by means of a Békésy audiometer. ${ }^{30}$ Warm or cold stimuli are steadily increased until the subject indicates stimulus perception by pressing a button. This ends stimulation and reverses the thermode temperature to the 


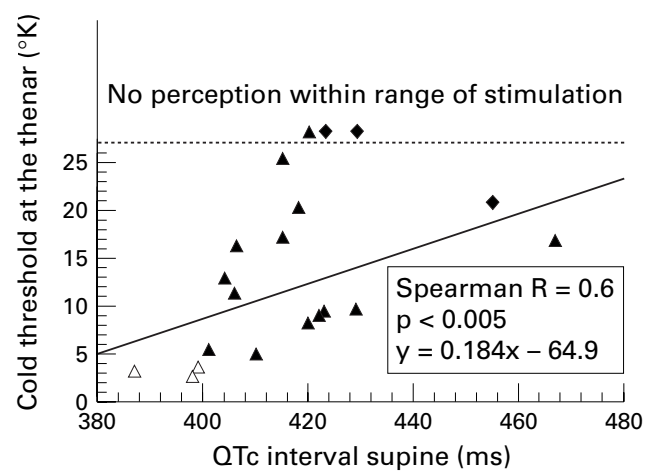

Significant correlation between cold perception thresholds at the thenar and supine QTc intervals in 20 patients with familial dysautonomia. Open triangles indicate normal cold perception. Filled symbols indicate impaired cold perception. Symbols above the dotted line represent patients with cold anaesthesia. Diamonds represent the three patients who had a cardiac arrest within 12 months after the study.

baseline. The difference between the signalled peak and the baseline temperature is registered.

Each warm or cold stimulus was applied five times. In addition, catch trials with one or two null stimuli were added to the five warm or cold stimuli. Warm or cold thresholds were determined as the average of the five peak to baseline differences. Heat pain thresholds were not evaluated separately as too many patients or parents did not agree to heat stimulation. Thresholds were determined at six body sites: at the cheek, at the shoulder $1.5-2.5 \mathrm{~cm}$ above the midpoint of the scapular spine, at the distal volar forearm $3 \mathrm{~cm}$ proximal to the wrist, at the thenar, at the distal medial calf $4-5 \mathrm{~cm}$ above the medial malleolus in the L4 dermatome, and at the lateral dorsum of the foot in the area innervated by the sural nerve. A $2.5 \mathrm{~cm} \times 5.0 \mathrm{~cm}$ thermode was used for testing at the shoulder, forearm, calf, and foot. A $1.5 \mathrm{~cm} \times 2.5 \mathrm{~cm}$ thermode was used at the cheek and thenar. Thresholds were compared with normative age related data established in 90 healthy controls aged 10 to 42 years ( 52 male, 38 female; mean 23.7 (10.6) years). Thermal perception was considered abnormal if thresholds exceeded mean normative values by more than $2 \mathrm{SD}$, if patients did not perceive all of the five repeated warm or cold stimuli, or if they reported paradoxical sensations or dysaesthesias. Before testing, we established that no patient was taking medication with central nervous effects inducing drowsiness and biassing cooperation.

With a temperature change rate of $1{ }^{\circ} \mathrm{C} / \mathrm{s}$ and a $0.1-0.2^{\circ} \mathrm{C}$ accuracy of the Thermotest, a reaction time of $0.1-0.2 \mathrm{~s}$ is sufficient for threshold assessment. To familiarise the study participants with the task of quickly responding to a stimulus, and to ensure adequate reaction time, we performed a simple test which had previously proved useful in children. ${ }^{31}$ The participants were instructed to tap on the examiner's knee as quickly as possible after the examiner had touched their own knee. A stopwatch was used to assure that reaction time did not exceed $0.1 \mathrm{~s}$.

To correlate QTc intervals with the severity of thermal perception dysfunction, QTc values were not only compared to warm and cold thresholds at the six body sites, but also to the number of abnormal perception sites found in each patient. The level of significance was set at $\mathrm{p}<0.05$. Data were analysed by a commercially available statistical program (SYSTAT, Evanston, IL, USA).

\section{Results}

Values for QTc were prolonged in four of the 20 patients. The QTc was prolonged in two patients when supine. A third patient developed prolongation when erect and a fourth postexercise.

Supine QTc intervals ranged from $387 \mathrm{~ms}$ to $467 \mathrm{~ms}$ (mean 417 (SD 18.7) ms), erect QTc intervals ranged from $395 \mathrm{~ms}$ to $483 \mathrm{~ms}$ (mean 417.2 ( SD 21.3) $\mathrm{ms}$ ) and postexercise QTc intervals from $398 \mathrm{~ms}$ to $465 \mathrm{~ms}$ (mean 417.7 (SD 21.8) ms). However, an erect QTc interval could only be determined in 15 patients and a postexercise QTc interval in 14 patients. One patient could not stand or exercise because of bilateral Charcot knee joints. Presyncopal symptoms developed in four patients when they assumed the erect position and in a fifth patient after exercise.

All participants had a reaction time $<0.1 \mathrm{~s}$ in the test preceeding thermal threshold assessment. Thermotest results were abnormal in all patients, but were more impaired in patients with prolonged QTc than in those with normal QTc values, and even worse in the six patients intolerant to standing or exercise. In all patients, thermal thresholds at the six tested sites were higher than in the control group (Mann-Whitney $U$ test: $\mathrm{p}<0.005)$. There was no consistent pattern of impaired thermal sensation (tables 1 and 2). The degree of threshold increase varied from one body site to the other, and the number of abnormal perception sites differed from one patient to another. The frequency of abnormal temperature perception was highest at the thenar and the distal volar forearm. At these sites, either cold or warm sensation was altered in all 20 patients. The site with the lowest frequency of abnormal results was the feet. Here, thresholds were abnormal in $75 \%$ of the patients.

In the 20 patients, perception of the five stimuli applied for threshold averaging at each of the six tested sites was incomplete in $15 \%$ of the warm and in $13.3 \%$ of the cold threshold determinations. Moreover, the individual variability of the five repeated stimuli was significantly higher in patients than in controls. At the different sites, variability of warm and cold perception was twofold to 14-fold higher in patients than in controls - that is, the threshold reproducibility was significantly lower in patients than in controls (Mann-Whitney $U$ test $\mathrm{p}<0.005$ ).

In the four patients with prolonged QTc intervals, warm and cold perception was abnormal at all of the six tested sites apart from one patient with normal warm perception at the foot. By contrast, patients with normal QTc intervals showed normal warm perception at $15.6 \%$ of the tested sites and normal cold perception at $17.7 \%$ of the sites. Similarly, in the six patients with familial dysautonomia 
Table 3 Comparison of QTc supine values to the individual number of body sites manifesting abnormal thermal perception in 20 patients with familial dysautonomia

\begin{tabular}{|c|c|c|c|c|c|}
\hline Patient No & $\begin{array}{l}\text { Body sites with } \\
\text { abnormal warm } \\
\text { perception (n) }\end{array}$ & $\begin{array}{l}\text { Body sites with } \\
\text { abnormal cold } \\
\text { perception }(n)\end{array}$ & $\begin{array}{l}\text { Body sites with abnormal } \\
\text { warm or cold perception }(n)\end{array}$ & QTc supine (ms) & $\begin{array}{l}\text { Intolerance to tilt } \\
(+) \text { or stair stepping } \\
(t)\end{array}$ \\
\hline 1 & 3 & 2 & 4 & 387 & \\
\hline 2 & 3 & 2 & 4 & 398 & \\
\hline 3 & 4 & 3 & 6 & 399 & \\
\hline 4 & 3 & 4 & 4 & 401 & \\
\hline 5 & 6 & 6 & 6 & 404 & \\
\hline 6 & 4 & 2 & 4 & 406 & \\
\hline 7 & 3 & 4 & 5 & 406 & $+\dagger$ \\
\hline 8 & 2 & 1 & 2 & 410 & \\
\hline 9 & 4 & 4 & 5 & 415 & \\
\hline 10 & 2 & 4 & 5 & 415 & \\
\hline 11 & 4 & 2 & 4 & 418 & $+\dagger$ \\
\hline 12 & 3 & 4 & 4 & 420 & \\
\hline 13 & 6 & 5 & 6 & 420 & \\
\hline 14 & 5 & 4 & 6 & 422 & \\
\hline 15 & 6 & 5 & 6 & 423 & \\
\hline (16) & (6) & (6) & (6) & (423) & $(+\dagger)$ \\
\hline 17 & 4 & 4 & 4 & 429 & $+t$ \\
\hline (18) & (6) & (6) & (6) & $(429)$ & $(\dagger)$ \\
\hline (19) & (6) & (6) & (6) & $(455)$ & \\
\hline 20 & 6 & 4 & 6 & 467 & $+t$ \\
\hline
\end{tabular}

The number of body sites with abnormal warm or cold thresholds found in each patient correlates with the QTc supine values. QTc supine values $v$ number of sites with abnormal cold perception: $\mathrm{Rs}=0.57 ; \mathrm{p}<0.01$. QTc supine values $v$ number of sites with abnormal warm perception: Rs $=0.59 ; \mathrm{p}<0.001$. QTc supine values $v$ number of sites with abnormal warm or cold perception: Rs $=0.46$; $\mathrm{p}<0.05$. Numbers in parentheses refer to the three patients who had cardiac arrest within 12 months after study.

intolerant of standing or exercise, warm and cold perception was abnormal at all tested sites whereas the 14 other patients with familial dysautonomia had normal perception for warmth at $19 \%$ of the sites and for cold at $20.2 \%$ of the sites. Moreover, the six patients presented with warm anaesthesia at $36.1 \%$ of the sites and cold anaesthesia at $33.3 \%$ of the sites compared with only $19 \%$ warm and $21.4 \%$ cold anaesthesia sites in the 14 patients tolerating physical stress. In all patients with familial dysautonomia, thermal threshold values of the six tested sites correlated with the supine QTc interval. However, the Spearman's rank correlation coefficient (Rs) varied for warm and cold thresholds and from one body site to another between 0.43 and 0.71 $(\mathrm{p}<0.05)$ (figure)

Supine QTc intervals correlated with the total number of sites showing abnormal warm or cold perception. The number of abnormal warm or cold thresholds at all the tested body sites correlated with QTc supine intervals at Rs values of 0.59 and 0.57 respectively $(\mathrm{p}<0.05$; table 3).

All patients underwent follow up examinations within 12 months of the study. Within this year, three of the patients had a cardiac arrest. Two of these patients had been unable to undergo QTc interval determination when erect or postexercise. In the third patient, the supine QTc interval had been prolonged. In all three, warm and cold perception was documented as abnormal at each of the six tested sites. The three patients either could not perceive the applied thermal stimuli or had highly raised thresholds.

\section{Discussion}

The cause of increased frequency of sudden death in the familial dysautonomia population has not been elucidated. Postmortem examination has never disclosed cardiac abnormalities. As familial dysautonomia is a disorder that primarily affects small fibre development and function, it is likely that sympathetic cardiac conduction as well as thermal sensory function are impaired to a similar extent. The degree to which patients are affected varies considerably. To date, no one has developed a clinical means of assessing severity of disease or method of predicting patients at increased risk of sudden death. Prolongation of the QTc interval is considered an indicator of cardiac risk, ${ }^{6-1025}$ and orthostatic presyncope indicates autonomic dysregulation. ${ }^{42-34}$ Our study shows that highly abnormal Thermotest results may be a predictor of increased cardiac autonomic risk. Thermotest results correlated with supine QTc interval values in all 20 patients, but coefficients of correlation varied between 0.43 and 0.71 . However, patients with prolongation of the QTc interval and especially patients intolerant of standing and exercise had Thermotest results significantly more abnormal than those of the patients with normal supine, posttilt, or postexercise QTc intervals. Three of our patients had a cardiac arrest within 12 months. One of these patients had a prolonged supine QTc interval and the other two developed presyncope with physical stress. All three patients had highly abnormal Thermotest results suggesting that they had pronounced impairment of both autonomic function and thermal perception.

Thermotest results showed that the distribution of small fibre dysfunction varies individually and does not follow a rather predictable pattern as seen in dying-back neuropathies. Thermal perception was more often impaired at the upper than the lower limbs. However, our Thermotest findings are consistent with various neuropathological studies of sural nerves, dorsal root, and sympathetic ganglia showing that the major pathological process in familial dysautonomia is one of insufficient development rather than postnatal degeneration. ${ }^{2} 12132324$ As the failure of small nerve fibre development varies individually, the pattern of thermal perception also varies from one patient to another and might afflict the 
upper limbs equally or more often than the lower limbs. ${ }^{32}$

Thermotest results are not a direct indicator of autonomic dysfunction, but previous studies of diabetic, uraemic, or alcoholic patients describe similarities between dysfunctions of temperature perception and autonomic regulation. ${ }^{19-21}$ In familial dysautonomia, the finding of such clinical similarities is supported by a similar degree of neuropathological abnormality in peripheral small nerve fibres and sympathetic ganglia. In familial dysautonomia, there is a reduction of unmyelinated sural nerve fibres to $5 \%-15 \%$ of the normal number and of neuron somas in the Gasserian and spinal ganglia to $50 \%$ of normal, and neuron somas in cervical and thoracical sympathetic ganglia are reduced to $27-37 \%$ of the normal number. ${ }^{12}{ }^{1322-24}$ The decrease in peripheral small fibres is clinically reflected by impaired thermal perception, ${ }^{12}{ }^{14}{ }^{32}$ and the reduction of cervical and thoracic ganglia accounts for cardiac autonomic dysfunction, ${ }^{23} 3536$ which might be recognised clinically by prolonged QTc interval values. In Romano-Ward long QT syndrome, an imbalance of left and right cervicothoracic sympathetic activity is assumed to induce prolongation of the QT interval. ${ }^{37-39}$

In patients with familial dysautonomia, determination of QTc intervals provides important information. Abnormal QTc intervals were detected in $20 \%$ of our patients. Glickstein et al reported QTc prolongation in 33\% of 54 patients with familial dysautonomia with an age distribution similar to our group (mean 24 (8.7) years). ${ }^{11}$ Limitations of QTc assessment seem to account for the different incidences. Eighty five per cent of patients studied by Glickstein et al could stand and exercise compared with only $70 \%$ of our group. We assume that Glickstein et $a l^{11}$ were able to show a higher incidence of QTc prolongation because more of their patients were able to tolerate stress tests. Stress tests are essential to unveil cardiac conduction abnormalities. In their control group (mean 24.7 (7.6) years), Glickstein et al found no QTc intervals exceeding $440 \mathrm{~ms}$ at rest, but one of the controls had a QTc prolongation of $452 \mathrm{~ms}$ after standing. ${ }^{11}$

Several previous studies show the need for stress tests to unmask prolongation of the QTC interval. ${ }^{40}$ Shimizu et $a l^{40}$ reported normal supine QTc values in five of 11 patients with Romano-Ward syndrome(45.5\%). With physical exercise all patients showed prolongation of the QTc interval. ${ }^{40}$ Gonin $e t a l^{42}$ and Sivieri et $a l^{43}$ reported that supine QTc values often fail to disclose diabetic cardiac autonomic neuropathy which had been diagnosed with other cardiovascular function tests such as Valsalva or Ewing manoeuvres. In the study of Gonin et al $57 \%$ of the patients with cardiac autonomic neuropathy had normal QTc intervals. ${ }^{42} \mathrm{Un}$ fortunately, cardiovascular function tests requiring physical effort might not be tolerated either by patients with familial dysautonomia manifesting presyncope during tilt or stair stepping. From our clinical experience, most patients with familial dysautonomia cannot perform Valsalva manoeuvres or other tests such as a sustained handgrip manoeuvre ${ }^{3344}$ requiring prolonged and steady coordination and cooperation.

Patients with normal supine QTc intervals but intolerance of stress tests require further evaluation of cardiac risk. Two of our patients who had a cardiac arrest could not undergo QTc stress tests. Therefore, alternative tests supporting the cardiac risk evaluation but requiring only little physical cooperation are desirable.

Thermotesting provides a non-invasive alternative that requires no physical effort. The method of limits ${ }^{29} 4546$ used in this study needs only slight patient cooperation; is easy to understand and thus yields highly reproducible results even in preschool children. ${ }^{31}$ In abundant studies the algorithm has proved useful in quantifying peripheral small fibre dysfunction. ${ }^{14} 151829454748$ Verdugo and Ochoa described as many as 36 different combinations of impaired thermal sensation patterns. ${ }^{14}$

In patients with familial dysautonomia, Thermotesting assesses the most prominent peripheral nerve dysfunction and thus refines the clinical grading of the disease. Thermotesting might also be useful for long term follow up studies. Most importantly, our results show that highly abnormal Thermotest results are an indirect suggestion of advanced cardiac autonomic dysfunction and merit further evaluation of cardiac function

1 Mahloudji M, Brunt PW, McKusick VA. Clinical neurological aspects of familial dysautonomia. $\mathcal{F}$ Neurol Sci 1969;11:383-95.

2 Pearson J, Axelrod FB, Dancis J. Current concepts of dysautonomia: neurologic defects. Ann NY Acad Sci 1974; 228:288-300.

3 Axelrod FB, Nachtigall R, Dancis J. Familial dysautonomia: diagnosis, pathogenesis and management. In: Schulman I, ed. Advances in pediatrics. Chicago: Year Book, 1974;21:7596.

4 Ziegler MG, Lake R, Kopin IJ. Deficient sympathetic response in familial dysautonomia. $N$ Engl $\mathcal{F} \mathrm{Med}$ 1976;294:630-3.

5 Axelrod FB, Abularrage JJ. Familial dysautonomia: a prospective study of survival. F Pediatr 1982;101:234-6.

6 Jervell A, Lange-Nielsen F. Congenital deaf mutism Jervell A, Lange-Nielsen F. Congenital deaf mutism:
functional heart disease with prolongation of the QT interval and sudden death. Am Heart $\mathcal{F}$ 1957;54:59-68.

7 Romano C, Gemme G, Pongiglione R. Aritmie cardiache rare dell'eta' pediatrica. Il Accessi sincopali fibrillazione ventricolare parossistica. Clin Pediatr 1963;45:656-83.

8 Ward OC. A new familial cardiac syndrome in children. fournal of the Irish Medical Association 1964;54:103-6.

9 Moss AJ, Schwartz PJ. Sudden death and the idiopathic long QT syndrome. Am $\mathcal{F}$ Med 1979;66:6-7.

10 Moss AJ, Schwartz PJ, Crampton RS, et al. The long QT syndrome: a prospective international study. Circulation 1985;1:17-21.

11 Glickstein JS, Schwartzman D, Friedman D, et al. Abnormalities of the corrected QT-interval in familial dysautonomia: an indicator of autonomic dysfunction. $\mathfrak{f}$ Pediatr 1993;6:925-8.

12 Aguayo AJ, Nair CPV, Bray GM. Peripheral nerve abnormalities in the Riley-Day syndrome: findings in a abnormalities in the Riley-Day syndrome: findin
sural nerve biopsy. Arch Neurol 1971;24:106-16.

13 Pearson J, Dancis J, Axelrod F, et al. The sural nerve in familial dysautonomia. I Neuropathol Exp Neurol 1975;34: 413-25.

14 Verdugo R, Ochoa JL. Quantitative somatosensory thermotest. A key method for functional evaluation of small calibre afferent channels. Brain 1992;115:893-913.

15 Hilz MJ, Claus D, Neundörfer B, et al. Is heat hypoalgesia a useful parameter in quantitative thermal testing of alcoholic polyneuropathy? Muscle Nerve 1994;17:1456-60.

16 San Antonio Conference on Diabetic Neuropathy. Proceedings of a Consensus Development Conference on Standardized Measures in Diabetic Neuropathy. Diabetes 1988; 37:1000-4.

17 Lindblom U, Tegner R. Thermal sensitivity in uremic neuropathy. Acta Neurol Scand 1985;71:290-4.

18 Navarro X, Kennedy WR. Evaluation of thermal and pain Navarro X, Kennedy WR. Evaluation of thermal and pain
sensitivity in type I diabetic patients. $\mathcal{F}$ Neurol Neurosurg Psychiatry 1991;54:60-4. 
19 Asbury AK. Neuropathies with renal failure, hepatic disorders, chronic respiratory insufficiency, and critical illness. In: Dyck PJ, Thomas PK, Griffin JW, et al, eds. Peripheral neuropathy. Philadelphia: WB Saunders, 1993 1251-65.

20 Thomas PK, Tomlinson DR. Diabetic and hypoglycemic neuropathy. In: Dyck PJ, Thomas PK, Griffin JW, et al, eds. Peripheral neuropathy. Philadelphia: WB Saunders, 1993: 1219-50.

21 Windebank AJ. Polyneuropathy due to nutritional deficiency and alcoholism. In: Dyck PJ, Thomas PK, Griffin JW, et al, eds. Peripheral neuropathy. Philadelphia: WB Saunders, 1993:1310-21.

22 Pearson J, Budzilovich, Finegold MJ. Sensory, motor and autonomic dysfunction: the nervous system in familial dysautonomia. Neurology 1971;21:486-93.

23 Pearson J, Pytel BA. Quantitative studies of sympathetic ganglia and spinal cord intermedio-lateral gray columns in ganglia and spinal cord intermedio-lateral gray colu

24 Pearson J, Pytel BA, Grover-Johnson N, et al. Quantitative studies of dorsal root ganglia and neuropathologic observa-
tions on spinal cords in familial dysautonomia. 7 Neurol Sci tions on spinal cor

25 Moss AJ. Measurement of the QT interval and the risk associated with QTc interval prolongation: a review. $\mathrm{Am} \mathcal{F} \mathrm{Car}^{-}$ diol 1993;72:23B-25B.

26 Bazett HC. An analysis of the time-relations of electrocardiograms. Heart 1920;7:353-70.

27 American Heart Association. Electrocardiographic test book 1956;1:157.

28 Schwartz PJ. Idiopathic long QT syndrome: Progress and questions. Am Heart f 1985;109:399-411.

29 Fruhstorfer H, Lindblom U, Schmidt WG. Method for quantitative estimation of thermal threshold in patients. $\mathcal{F}$ Neurol Neurosurg Psychiatry 1976;39:1071-5.

30 Békésy G. A new audiometer. Acta Otolaryngol (Stockh) 1947;35:411-22.

31 Hilz MJ, Glorius SE, Schweibold G, et al. Quantitative thermal perception testing in preschool children. Muscle Nerve

32 Axelrod FB, Iyer K, Fish I, et al. Progressive sensory loss in familial dysautonomia. Pediatrics 1981;67:517-22.

33 Mathias CJ, Bannister R. Investigation of autonomic disorders. In: Bannister R, Mathias CJ, eds. Autonomic failure. Oxford: Oxford University Press, 1993:258-64.

34 Wieler W. Non-invasive continuous recording of heart rate and blood pressure in the evaluation of neurocardiovascular control. In: Bannister R, Mathias CJ, eds. Autonomic failure. Oxford: Oxford University Press, 1993:291-311.
35 Maayan C, Axelrod FB, Akselrod S, et al. Evaluation of autonomic dysfunction in familial dysautonomia by power pectral analysis. F Auton Nerv Syst 1987;21:51-8.

36 Mason DT, Kopin IJ, Braunwald E. Abnormalities in reflex control of the circulation in familial dysautonomia. $A m \mathcal{F}$ Med 1966;41:898-909.

37 Schwartz PJ, Periti M, Malliani A. The long Q-T syndrome. Am Heart F 1975;89:378-90.

38 Curtiss EI, Heibel RH, Shaver JA. Autonomic maneuvers in hereditary Q-T interval prolongation (Romano-Ward syndrome). Am Heart 7 1978;95:420-8.

39 Göhl K, Feistel H, Weikl A, et al. Congenital myocardial sympathetic dysinnervation (CMSD) - a structural defect of idiopathic long QT syndrome. Pace 1991;14:1544-53.

40 Shimizu W, Ohe T, Kurita T, et al. Differential response of QTU interval to exercise, isoproterenol, and atrial pacing in patients with congenital long QT-syndrome. Pace 1991;14:1966-70.

41 Vincent GM, Jaiswal D, Timothy KW. Effects of exercise on heart rate, QT, QTC, and QT/QS2 in the Romano-Ward heart rate, QT, QTC, and QT/QS2 in the Romano-Ward 503.

42 Gonin JM, Kadrofske MM, Schmaltz S, et al. Corrected QT interval prolongation as diagnostic tool for assessment of cardiac autonomic neuropathy in diabetes mellitus. Diabetes Care 1990;13:68-71.

43 Sivieri R, Veglio M, Chinaglia A, et al. Prevalence of QT prolongation in a type 1 diabetic population and its association with autonomic neuropathy. Diabetic Med 1993;10: 920-4.

44 Appenzeller O. The autonomic nervous system. An introduction to basic and clinical concepts. Amsterdam, New York, Oxford: Elsevier, 1990:179-82.

45 Claus D, Hilz MJ, Hummer I, et al. Methods of measurement of thermal thresholds. Acta Neurol Scand 1987;76:288-96

46 Claus D, Hilz MJ, Neundörfer B. Thermal discrimination thresholds: a comparison of different methods. Acta Neurol Scand 1990;81:533-40.

47 Hansson P, Lindblom U, Lindström P. Graded assessment and classification of impaired temperature sensibility in patients with diabetic polyneuropathy. $\mathcal{F}$ Neurol Neurosurg Psychiatry 1991;54:527-30

48 Ziegler D, Mayer P, Gries FA. Evaluation of thermal, pain, and vibration sensation thresholds in newly diagnosed type I diabetic patients. $\mathcal{F}$ Neurol Neurosurg Psychiatry 1988;51: 1420-4 